\title{
SOCIÉTÉ HYDROTECHNIQUE DE FRANCE
}

Comité technique - Session no 127 - Paris - 20 et 21 mars 1985

FONCTIONNEMENT DES TURBOMACHINES A DÉBIT PARTIEL

\section{Influence de la géométrie des structures situées à l'aspiration d'une pompe sur les courbes caractéristiques à débit partiel.}

\author{
Influence of the geometry of the structures \\ located at the suction of a pump \\ on the characteristic curves at partial flow rate
}

\author{
H. Guesnon \\ Framatome, Paris \\ J.F. Lapray \\ Société Bergeron, Paris
}

Lorsque le débit d'une turbomachine diminue en dessous de la valeur critique Qk1, l'écoulement à l'entrée de la roue se modifie. Une zone centrale avec peu de prérotation alimente la roue. Dans la zone annulaire, l'écoulement de recirculation en provenance de la roue interfère avec l'écoulement plus ou moins sain induit par les structures situées à l'amont de celle-ci.

Une analyse à partir de résultats expérimentaux fournis par des constructeurs, complétée par une recherche bibliographique, montre, en fonction des géométries rencontrées à l'aspiration, l'influence des différentes formes d'écoulement sur la variation des courbes caractéristiques.

On s'attache dans un premier temps à rechercher, examiner et expliquer les modes d'influence des coudes d'aspiration, chambres d'aspiration et autres dispositifs annexes.

On essaie d'analyser ensuite quelques cas de transformations ou modifications de la géométrie de la roue.

When the flow rate of a turbomachine decreases below the critical value, Qk1, the flow is modified on the impeller inlet. The impeller is supplied by a central area with low prerotation. In the annular space, the recirculation flow from the impeller interferes with the more or less sound flow induced by the structures located upstream of the impeller.

Analysis of the experimental data supplied by the manufacturers supplemented by bibliographical data shows the influence of various forms of flow on the variation of the characteristic curves as a function of the geometries encountered in the suction.

First, the modes of influence of the suction bends, suction chambers and other ancillary systems are identified, examined and explained.

Next, a few cases of transformation or modification of the impeller geometry are analyzed. 


\section{Influence de la géométrie des structures situées à l'aspiration d'une pompe sur les courbes caractéristiques à débit partiel}

\section{RÉSUMÉ}

Lorsque le débit d'une turbomachine diminue en dessous de la valeur critique Qk1, l'écoulement à l'entrée de la roue se modifie. Une zone centrale avec peu de prérotation al imente la roue. Dans la zone annulaire l'écoulement de recirculation en provenance de la roue interfêre avec 1'êcoulement plus ou moins sain induit par les structures situées à l'amont de celle-ci.

Une analyse à partir de résultats expérimentaux fournis par des constructeurs, complētée par une recherche bibliographique montre, en fonction des géométries rencontrées à l'aspiration, l'influence des différentes formes d'écoulement sur la variation des courbes caractêristiques.

On s'attache, dans un premier temps à rechercher, examiner et expliquer les modes $d^{\prime}$ influence des coudes d'aspiration, chambres d'aspiration et autres dispositifs annexes.

On essaie d'analyser ensuite quelques cas de transformations ou modifications de la géométrie de la roue.

\section{INTRODUCTION}

Le fonctionnement d'une pompe centrifuge à un débit inférieur au débit critique de la recirculation $Q \mathrm{Kl}$, engendre dans l'espace rotorique situé près de l'entrée de la roue un écoulement complexe.

1. DESCRIPTION ET STRUCTURE DE L'ECOULEMENT DANS L'ESPACE ROTORIQUE A DEBIT PARTIEL

La figure 1 montre une image schêmatique de 1 'écoulement qui peut être divisê en deux zones [1]:

a) A la përiphérie du conduit une zone annulaire est alimentée par un courant de recirculation venant de la roue. Dans cette zone le fluide possède une composante tangentielle très élevée qui s'accroit au fur et à mesure que le débit de la pompe diminue. En s'éloignant de la roue la composante tangentielle diminue et, à une certaine distance, variable en fonction du débit pompe, l'écoulement de recirculation se retourne et réalimente la roue.

b) La zone centrale qui débite dans la roue possède un écoulement, sans prérotation autre que celle induite par les organes d'aspiration situés en amont.

Entre les deux zonєs, pour des débits légẽrement inférieurs au dẻbit de recirculation Qk1 on observe un écoulement dirigé vers la roue, mais dont la composante tangentielle est grande. Lorsque le débit se réduit, cette zone intermédiaire gagne sur la zone centrale saine et pour les très petits débits tout l'espace central débitant dans la roue est occupé par un écoulement avec une composante tangentielle dont le sens est celui de la rotation de la roue.

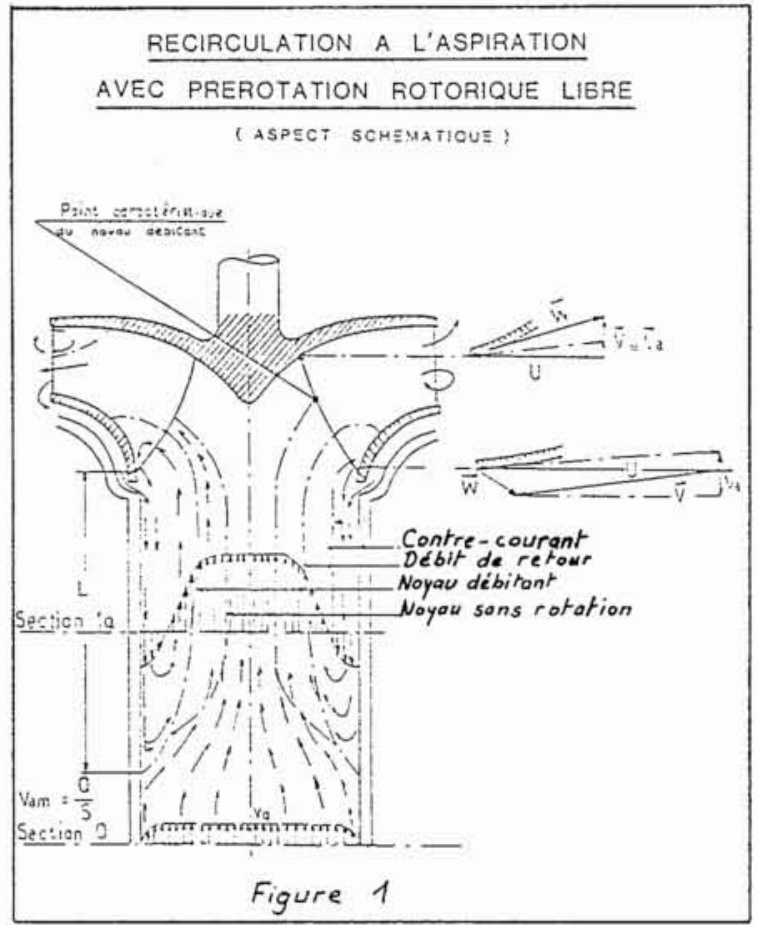


La figure 2 donne, à titre d'exemple, les cartes de vitesses relevées dans deux sections d'une tuyauterie à l'aspiration d'une pompe centrifuge de $\mathrm{N}_{\mathrm{S}}=46 \cdot[2]$

Dans 1a section 1 , au rayon $\mathrm{R}$ extếrieur la vitesse tangentielle, à débit nul, prend une valeur voisine de $0,8 U_{10}, U_{10}$ est la vitesse d'entrainement périphérique de 1 'oeillard de la roue. Cette vitesse tombe à $0,42 U_{10}$ dans la section 2 situee plus en amont de l'entrêe de la roue.

Les cartes de vitesse mettent en avant 1 'importance des gradients de vitesse radiale et tangentielle, gẻnérateurs de forces de frottement élevées qui dissipent une grande partie de l'énergie extraite de la roue par le débit de recirculation [3]. Cette energie, à débit nul, atteind $30 \%$ dè ra puissance nominale d'une pompe hêlicocentrifuge de $N_{s}=96$. Un autre auteur [5] a mesuré, à dēbit nul, une perte totale d'énergie dans la tuyauterie d'aspiration de 1 'ordre $0,3 \mathrm{U}_{10^{2 / 2}} \mathrm{~g}$ pour une pompe centrifuge $\mathrm{N}_{\mathrm{S}}=50$ environ.

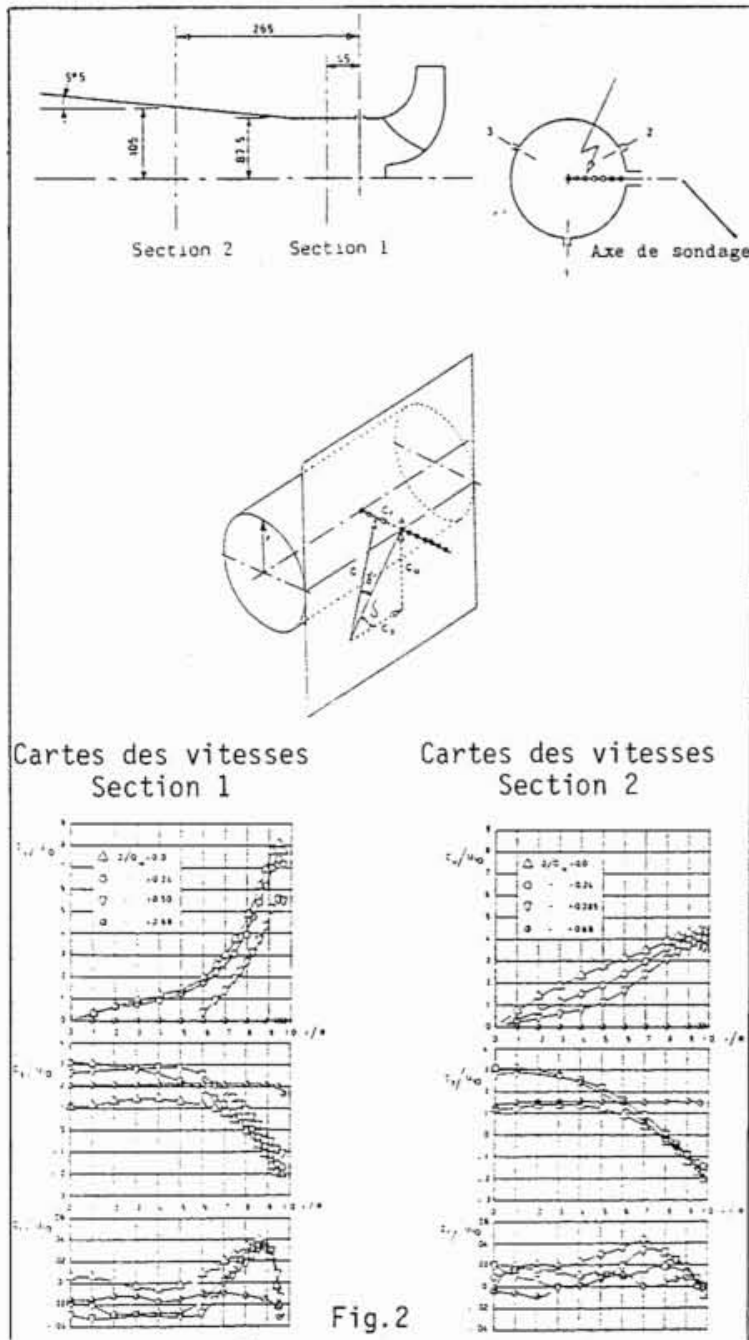

d'après Ferrini (réf.2)
De nombreux auteurs, cités en rëfërences, ont conduit des expérimentations du même type, le plus souvent sur des pompes alimentées par des tuyauteries droites. La structure de l'écoulement reste assez voisine de celle décrite ici, même pour des pompes de vitesses spécifiques élevées. Cependant, pour ces' derniêres les valeurs des paramètres caractéristiques à débit partiel représentent un fort pourcentage des caractéristiques au point nominal. La géométrie à 1 'aspiration de ce type de pompe est essentielle dans leur comportement à débit partiel.

Les mesures réalisées montrent également que les écoulements sont axisymétriques, des essais plus récents semblent également mettre en évidence le caractẽre fluctuant des vecteurs dans ces zones.

Des recherches, plus fondamentales, pour expliquer et comprendre les mécanjsmes de la recirculation ont été entreprises[7]. Le phënomène met en jeu un grand nombre de paramètres géométriques liês à la roue et à la géométrie de I'espace rotorique. Parmi quelques paramẽtres impurtants on peut citer entre autres :

- le rapport $\frac{D_{1 C}}{D_{1 p}}$

- les angles d'entrée des aubes $\beta_{1 c}, \beta_{1 p}$.

- le profil et la portance des aubes

- la forme de l'arête d'entrée

- le nombre d'aubes,

- la rugositê des conduites, etc...

Mais, les conditions aux limites à l'amont de la roue jouent un très grand rôle et doivent être prises en considération.

\section{INTERACTION POMPE-ESPACE STATORIQUE AMONT}

Dans la pratique industrielle, il est très rare que les pompes puissent être alimentées par une longue tuyauterie droite. Certaines machines sont construites avec un coude qui fait parfois partie intégrante du corps de pompe (culotte d'aspiration, coude à prérotation, etc...). Dans d'autres cas les contingences d'encombrement, la recherche d'enfoncement minimum, les dispositifs anti-statoriques Vortex, les croisillons, etc.. font que les espaces amont prennent des formes variēes.

Dans ces conditions, l'écoulement de recirculation est fortement modifié et influencé par ces nouvelles formes amont, souvent axisymétriques, ainsi que par la structure de l'écoulement qu'elles délivrent (prêrotation induite voulue ou non par exemple). La roue est alors alimentée par un nouvel écoulement dont les paramètres ont été changés (moment cinétique, gradient de vitesse, etc..).

L'écoulement dans la roue s'en trouve modifié et les caractéristiques à dëbit partiel prennent de nouvelles valeurs dont les variations sont importantes et que seuls des essais expërimentaux peuvent quantifier. 
Nous verrons dans la suite de notre exposé, et à travers quelques exemples expérimentaux, comment les formes statoriques amont, peuvent influer sur les caractēristiques hydrauliques.

\section{INFLUENCE D'UN COUDE D'ASPIRATION}

De manière générale, un coude situé à l'aspiration d'une pompe peut avoir un effet perturbateur ou régulateur sur l'écoulement en sortie de ce coude :

\section{Effet perturbateur}

Un coude simple à $90^{\circ}$, à section et ã rayon de courbure constants, entraine une distorsion de 1 'écoulement dans la section de sortie. Une dissymétrie des vitesses méridiennes, ainsi qu'un écoulement secondaire, formé d'une double torche, apparaissent en sortie du coude.

De plus, l'effet de perturbation de l'êcoulement est accru dans le cas d'une succession de plusieurs coudes non coplanaires.

\section{Effet régulateur}

Du fait de son intêrêt évident, l'effet régulateur d'un coude a étê étudiê depuis longtemps par un grand nombre d'expérimentateurs. Cette solution est utilisée aujourd'hui dans de nombreuses applications partout où un changement d'orientation de l'écoulement avant la roue, est nécessaire.

Le principe mis en oeuvre, réside pour 1 'essentiel dans une accēlēration importante de 1 'écoulement, entre l'entrée et la sortie du coude, entrainant un amortissement des perturbations existant à l'entrée du coude.

\section{Etude des écoulements dans un coude}

Si les études expêrimentales s'accordent à constater une certaine distorsion du profil des vitesses à la sortie d'un coude, il apparait cependant une hétêrogénéité dans les rêsultats constatés. En effet, comme on peut le voir sur la figure 3 , les essais [3], [27] mettent en évidence une accêlération des filets externes, dans d'autres cas [25], [20] il est constatê une accélération plus importante des vitesses côté intërieur (fig.4). Il est clair que dans ce cas, des paramètres secondaires tels que : rayon de courbure, vitesse initiale, décollements, variation de section ou de rayon, viennent influer sur l'êcoulement.
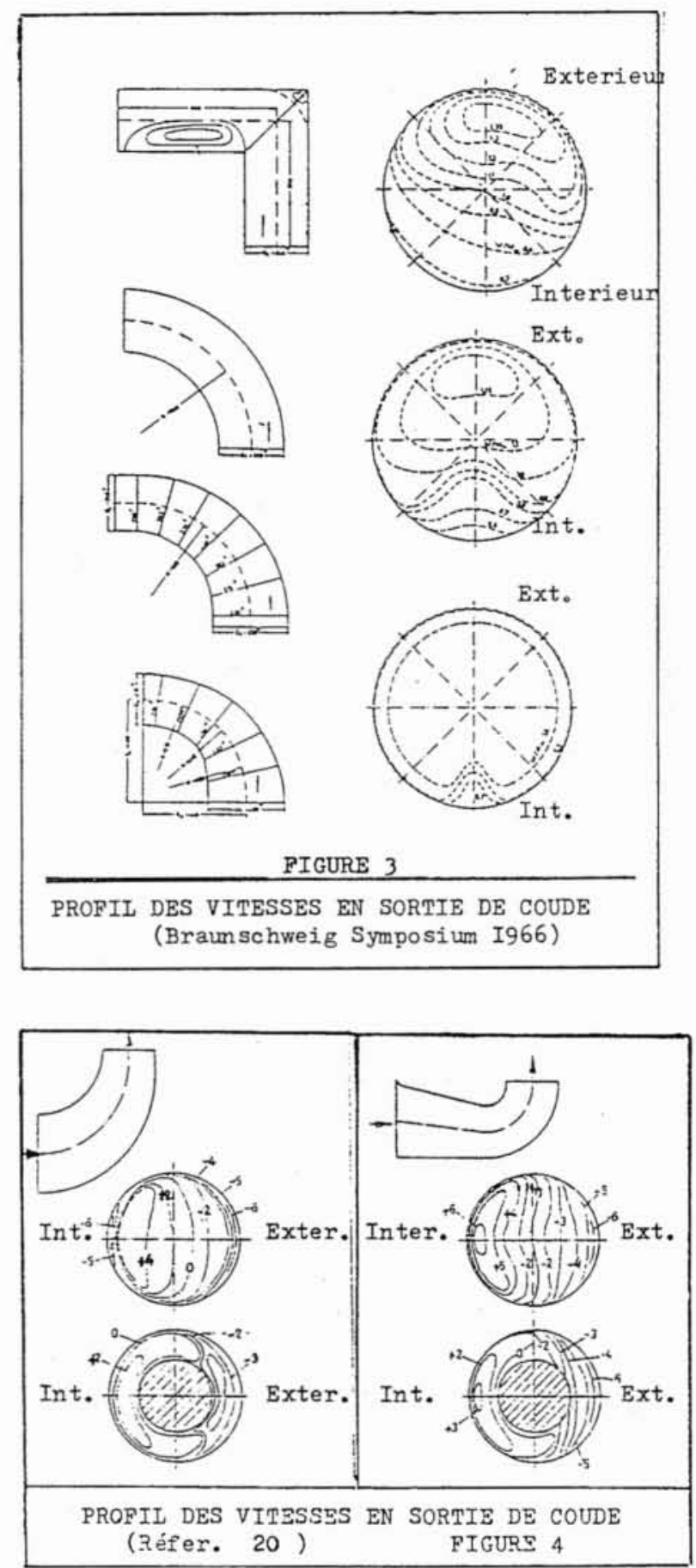

FIGURE 4

Interaction entre écoulement principal et écoulement de recírculation

Le problème se complique dans le cas oũ le coude se situe à proximité de l'entrée de la roue : l'écoulement induit par la roue en recirculation, et celui induit par le coude, se superposent et se contrarient. 
Par exemple, les essais de Murakami-Heya[3], soulignent les résultats suivants :

- à bas débit, dans la zone de recirculation, la forme de l'écoulement est pratiquement celle d'une tuyauterie droite, c'est-à-dire que l'écoulement de recirculation est prépondérant et impose sa loi de vitesse et de répartition de pression symétrique. Il faut pour cela que 1 'écoulement de recirculation soit suffisamment intense, et puisse remonter dans le coude. - lorsque le débit augmente, l'écoulement de recirculation recule progressivement et laisse apparaitre (voir fig.5) un écoulement secondaire provenant du coude, détruisant la symétrie initiale. Il apparait alors une prérotation positive ou négative.

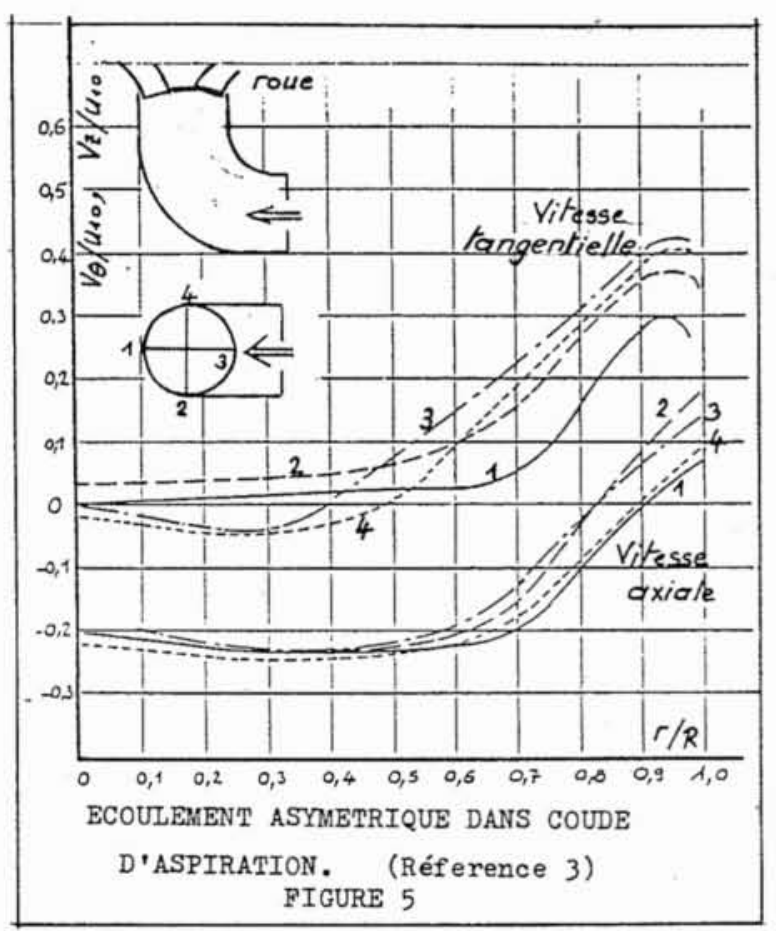

- de plus, quelle que soit son intensité, 1 'écoulement de recirculation ne peut remonter à $l^{\prime}$ 'amont d'un coude à $90^{\circ}$, mais influe sur 1 'écoulement amont d'un coude à $45^{\circ}$ (fig.6).

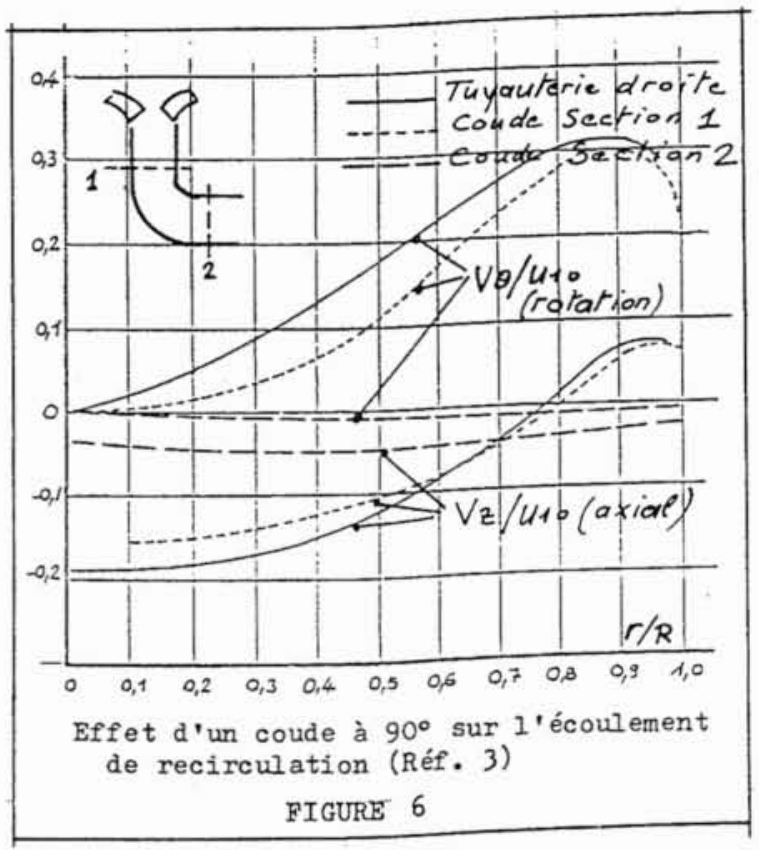

Variation des caractĕristiques hydrauliques après un coude

La distorsion plus ou moins importante de l'écoulement constatêe à la sortie du coude modifie la charge aérodynamique sur 1'aubage et par conséquent, modifie également la caractéristique hydraulique de la pompe. Cet effet aérodynamique étant prépondérant pour les pompes de grand Ns, la sensibilité à un écoulement incident perturbé, et la variation des courbes caractéristiques en seront plus importantes : - BERGERON [27], à partir d'essais faits sur une pompe de Ns 85 , met en évidence une augmentation de hauteur $(+8 \%)$ et surtout de puissance $(+40 \%)$, dans le cas d'utilisation d'un coude convergent. (voir figure 7 ).

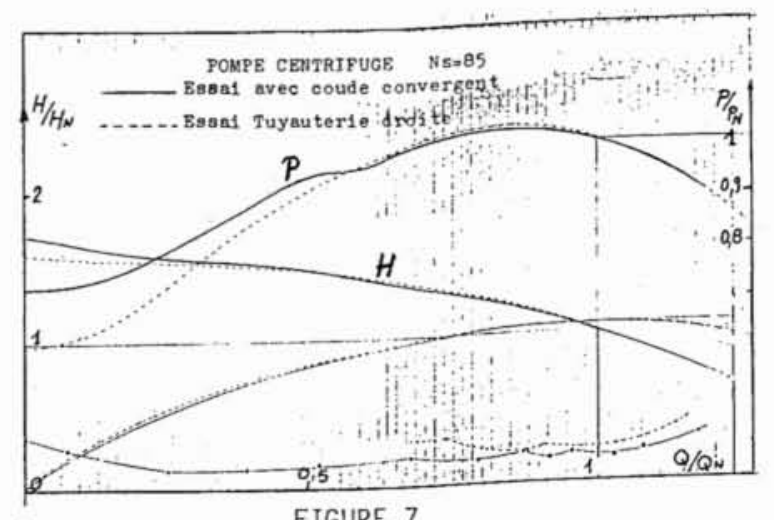

FIGURE 7

- Les essais faits par LIU-DA-KAI [18] - Les essais faits par LIU-DA-Karent la sensibilité des caractéristiques hydrauliques d'une pompe axiale, en fonction de certains paramètres dimensionnels des coudes d'aspiration. (voir Figure 8). 
Par exemple, I'augmentation de l'enfoncement du coude (passage de $H / D=1,5$ à $H / D=1,7$ ) permet d'augmenter la hauteur à $+7 \%$ à débit optimum.

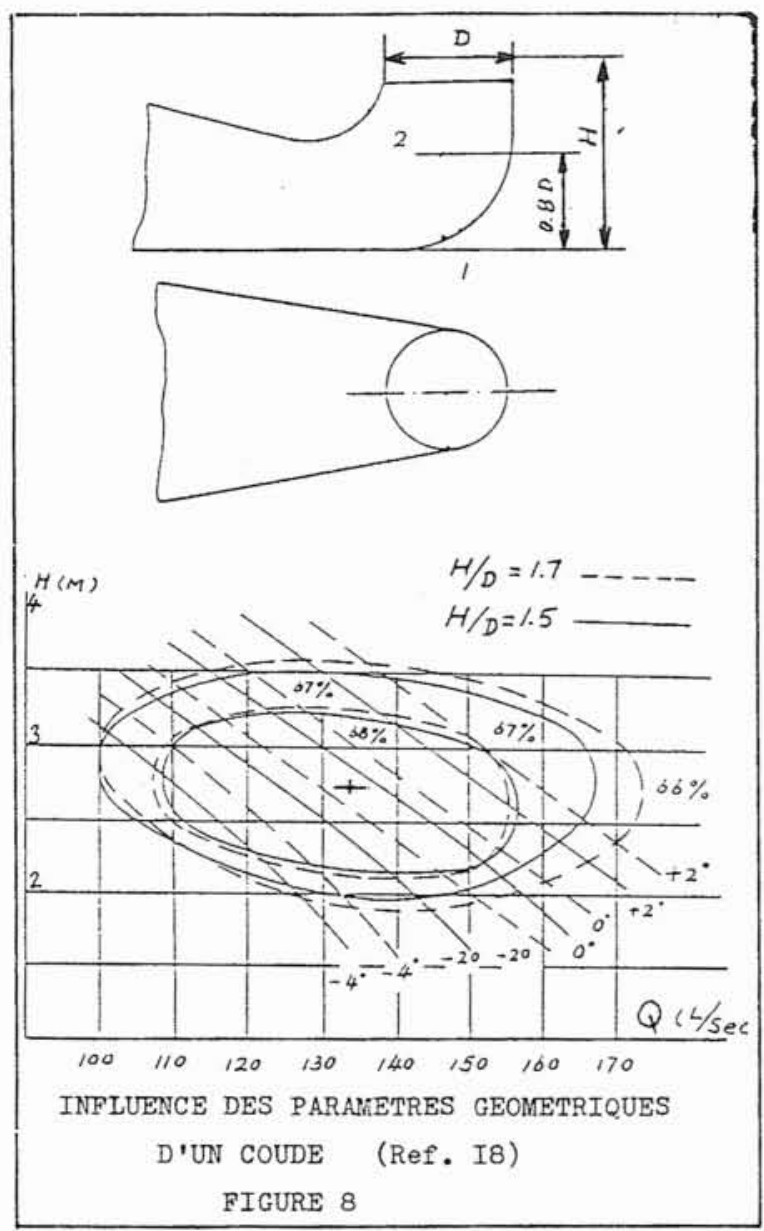

- Enfin, les essais de Scnöneberger [14] présentent l'influence de différentes géométries de coudes d'aspiration sur le comportement en cavitation, pour une pompe de type centrifuge : on note en particulier :

- une augmentation très sensible $(+20 \%)$ du NPSH critique $(0 \% \Delta H)$ en fonction du type de coude utilisé

. par contre, aucune variation du point, NPSH pleine cavitation, quelque soit le coude.

\section{Exemple d'essais paramètriques}

Des essais systématiques très complets (voir figure 9) ont été rẻalisés par un constructeur

[27] sur des pompes de type centrifuge, hếlico-centrifuge, et semi-axiale. Les essais portent sur la mesure des courbes caractéristiques complètes (Q-H- NPSH) pour les pompes de Ns 40 à 150, en association avec des aspirations de forme diffërente. En particulier les différences entre entrée droite et coudes à section constante, ou au contraire à section variable ont étê examinëes.
De ces essais, peuvent être dêgagées les tendances suivantes :

- un coude d'aspiration à section constante n'entraine que peu de variation sur la courbe Q-H, par rapport au cas d'aspiration droite, et ceci quelque soit le Ns (dans la gamme étudiēe),

- par contre, avec ce même coude à section constante, le NPSHR se trouve considërabilement augmenté (x1,5 à 2),

- l'utilisation d'un coude d'accélération (rapport des vitesses entrée-sortie 2,5) entraine une augmentation de la hauteur à vanne fermée $(+8 \%$ pour Ns 100 et $+30 \%$ pour Ns $150)$, et confirme ainsi la tendance connue, - dans certains cas, la mise en place d'un coude d'accélēration entraine l'apparition d'une zone d'instabilité ou son accentuation, dans la zone 0,7 QN,

- enfin les essais d'une même hydraulique avec diffërents coudes montrent la difficulté de concilier l'augmentation de stabilité (requiert 1 coude avec accélération localisée avant la roue), avec la conservation d'un NPSH requis faible (entrée droite ou coude à section constante).

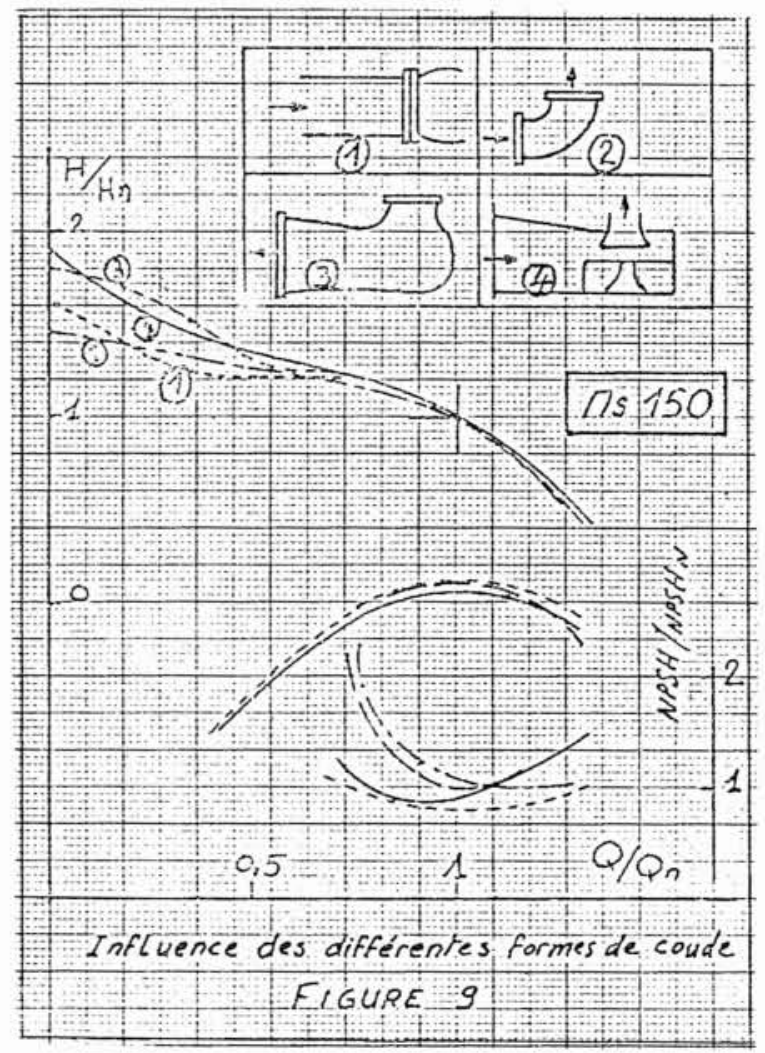

Conclusion sur l'influence gênérale d'un coude

Il apparait difficile, à travers ces quelques exemples, de tirer des conclusions générales quant à l'influence d'un coude. Ceci est dû à la très grande variété de gêométries possibles, pour la roue et pour le coude. 
On peut avancer par exemple les points suivants :

1. Il n'existe pas une tendance unique de variation des courbes $Q-H$, sous l'effet d'un coude. Il faut en particulier distinguer entre les différents types de coude, à section constante et/ou à section variable pour lesquels le rapport d'accêlération, le rayon de courbure et la zone d'accélération jouent un rôle prépondërant.

2. Quelque soit le type de coude, le NPSH est fortement influencé (en hausse) dans la zone des débits partiels.

3. Par contre, la courbe $Q-H$ n'est pas toujours et systẻmatiquement augmentée à débit partiel, dans le cas d'utilisation d'un coude.

4. Il existe une interaction certaire entre les écoulements induits par le coude, et le courant de recirculation. En particulier, si l'écoulement dans un coude régulier, à section constante a étế clairrement explicité par l'étude de Murakarni [3], il serait nécessaire cependant d'en vêrifier les conclusions dans le cas de coudes à section variable : champ des vitesses dans le coude, interaction des écoulements entre roue, et coude, influence du Ns (comment diffuse le courant de recirculation?).

5. Afin d'expliciter la variation des caractéristiques observées, un programme d'ëtude d'une aspiration de pompe avec coude devrait comporter par exemple les étapes suivantes :

- étude des écoulements dans le coude seul (sans roue) (visualisation, champ de vitesses, pertes de charge, étude des décollements...) - étude couplêe, de l'ensemble coude + roue : avec visualisation du champ de vitesse, et mesure des caractéristiques complètes de pompe (Q-H, NPSH)

- comparaison avec performance pompe, à entrée droite

Toutes ces étapes étant nécessaires à l'étude et à la compréhension de la corrêlation entre forme d'un coude, et caractéristique hydraulique.

\section{CHAMBRES D'ASPIRATION}

Il existe un très grand nombre de travaux et d'études se rapportant au vaste domaine des espaces d'aspiration pour pompes verticales (coudes d'aspiration, et chambres d'aspiration). Toutes ces études sont principalement orientẻes vers l'analyse des aberrations ou anomalies d'écoulement, telles que prérotation, vortex, tourbillons, torches. Elles ont pour objectif la recherche et l'établissement de règles de tracé et de recommandations générales, permettant une définition optimale des espaces d'aspiration, et garantissant l'obtention d'un écoulement sain à l'entrée de la roue.

Notre propos n'étant pas de reprēciser ces règles de l'art, seuls quelques exemples seront donnés en annexe.

\section{Influence sur les courbes caractéristiques}

On peut constater que si l'on trouve à profusion des êtudes de cas, et des règles de tracé de nature statistique, rares sont les essais paramétriques effectués dans le but d'obtenir des résultats fondamentaux.

Le problème est de définir au stade Projet, les caractéristiques prêvisionnelles d'une pompe, installée dans une chambre d'aspiration d'une configuration donnêe. L'extrapolation à partir de courbes de base, établies sur machines modèles, avec entrée droite et tuyauterie, ne peut être très rigoureuse dans le cas d'application à une pompe de taille importante située dans une chambre d'aspiration particulière, d'oû des écarts parfois élevês entre courbe "usine", et courbe "site".

Deux cas sont à distinguer, qui peuvent conduire à une modification importante des caractéristiques :

\section{Ecoulement induit par la chambre d'aspiration}

Sans tenir compte des aberrations d'écoulement locales, telles que torches ou vortex, un mouvement d'ensemble axisymêtrique du fluide peut conduire à une prerotation positive ou négative, modifiant considërablement la caractëristique totale de la pompe y compris à grand débit (voir figure 10).

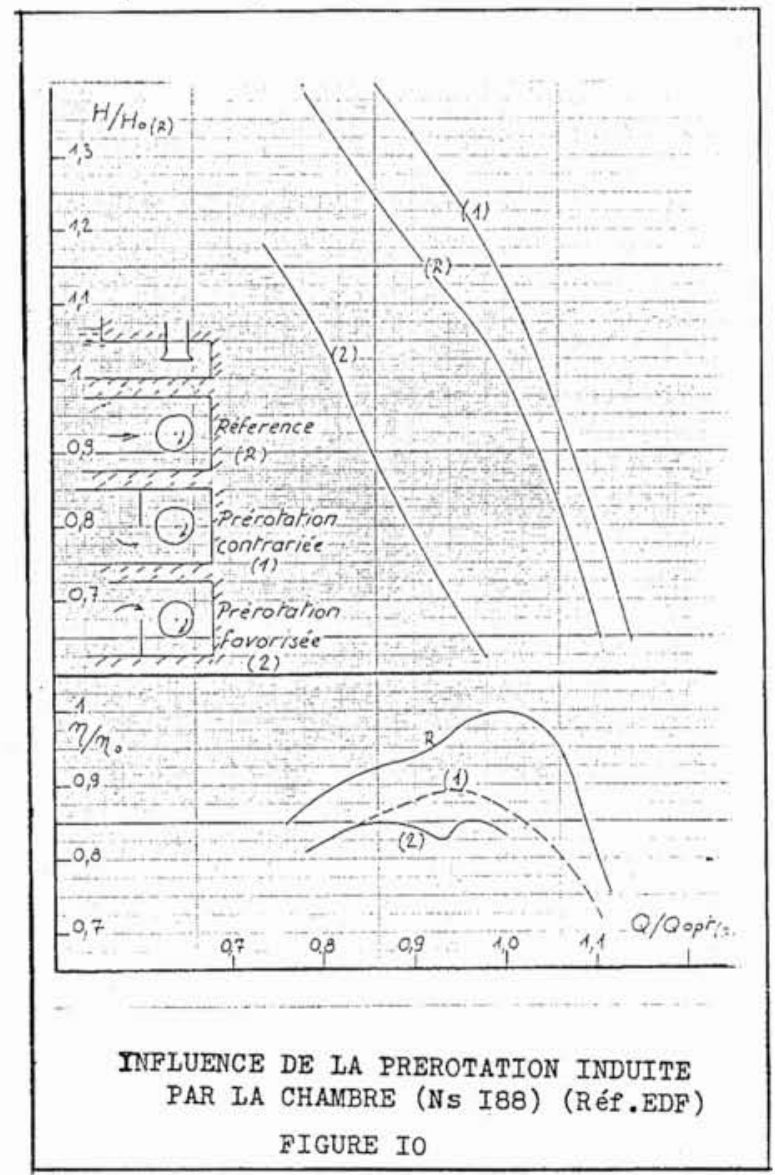




\section{Ecoulement de recirculation}

La difficultē est d'estimer l'effet de 1 'écoulement de recirculation à débit partiel, sur la caractéristique de hauteur et puissance. En effet, selon 1'importance de la chambre dans laquelle est plongée la pompe, l'écoulement de recirculation diffuse plus ou moins localement: un écoulement de recirculation dans une chambre large $\mathrm{n}$ 'a pas d'influence sur la courbe $\mathrm{Q}-\mathrm{H}$, au contraire un écoulement de recirculation dans une chambre étroite diminue considêrablement les caractéristiques de hauteur et puissance.

Paterson a montré [11] quelle peut être 1 'importance extrême de ces deux conditions limites sur la variation d'une courbe caractéristique (+ $60 \%$ à débit nu1) ; des diagrammes établis par cet auteur, après une sêrie d'essais systêmatiques, précisent la diminution de caractêristiques en fonction des dimensions de la chambre et 1 'influence du Ns sur 1 'augmentation de la caractēristique (voir figure 11).
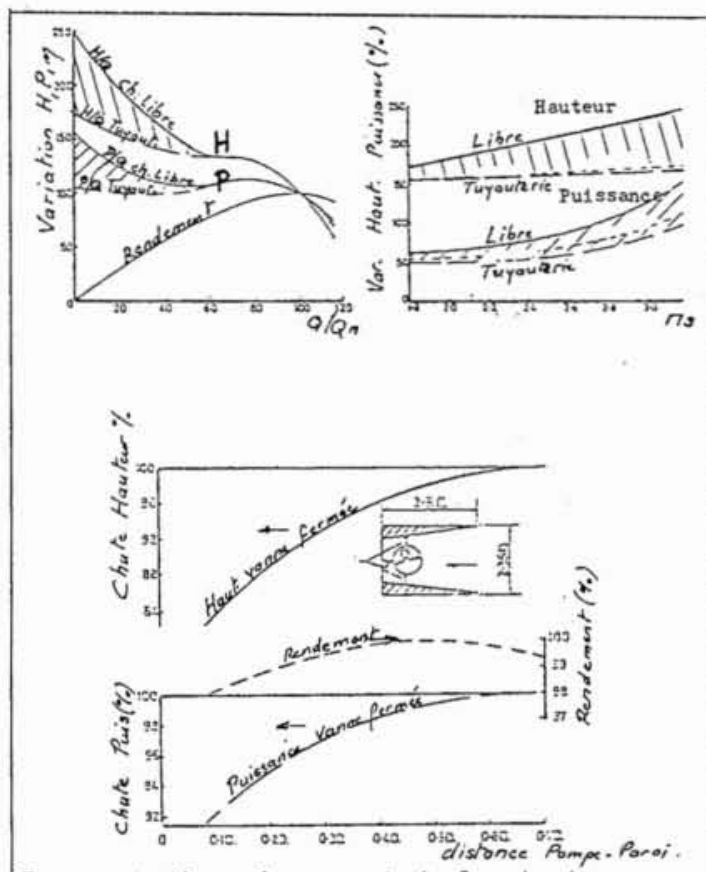

Forme et dimensionnement de la chambre d'aspiration : influence sur les caractéristiques

\section{FIGURE 11}

\section{ASPIRATION EN CUVE}

En règle gếnérale, les cuves d'aspiration sont utilisées dans le cas de volumes disponibles réduits, ou d'espaces confinēs, de surfaces au sol limitêes, ou bien dans le but d'augmentation du NPSH disponible par enfoncement de la pompe dans le sol.

\section{Formes d'êcoulement}

Les conséquences de cette disposition sont essentiellement l'existence de vitesses d'approche êlevées ( 2 à $6 \mathrm{~m} / \mathrm{s}$ ), des changements brusques de direction $\left(180^{\circ}\right)$ et une distribution des vitesses, irrégulière et anarchique au voisinage de l'entrée de la roue; tous ces phênomènes induisant des niveaux de bruit et de vibrations particulièrement êlevês.

A débit partiel, la mauvaise qualité gẻnérale de l'écoulement et les perturbations hydrauliques (chocs, tourbillons) se trouvent ampl ifiées par suite de l'espace restreint, existant ã 1 'amont de la roue. Il en rẻsulte une augmentation très importante du niveau vibratoire de la machine, et dans certains cas un écoulement à caractère pulsatoire, avec formation de vortex et d'instabilitês hydrauliques [26].

\section{Influence sur les caractëristiques}

Bien que d'un emploi relativement fréquent dans l'industrie (pétrole par exemple), il est très difficile cependant par manque de résultats expérimentaux d'analyser l'incidence de cette disposition sur les caractêristiques, et même de fixer des tendances et des limites pratiques d'utilisation.

\section{Dispositions technologiques}

Dans certains cas, des dispositifs particuliers, mettant en oeuvre des principes différents (croisillons anti-vortex, cones ou pièces de guidage, utilisation du phénomène de couche limite à travers une grille) peuvent jouer un rôle important, et nécessaire pour les pompes ã Ns êlevé par exemple. (voir figure 12).

\begin{tabular}{|c|c|}
\hline & $\begin{array}{l}\text { Cône sous trompette: } \\
\text { Elimine la possibilité de } \\
\text { formation de torche centrale. }\end{array}$ \\
\hline & $\begin{array}{l}\text { Croisillon anti-vortex éloi- } \\
\text { gnét } \\
\text { - Croisillon de résction in- } \\
\text { dépendant de la ponpe. } \\
\text { - Evite la mise en rotation } \\
\text { de } 1 \text { 'eau. }\end{array}$ \\
\hline & $\begin{array}{l}\text { Crolsillon anti-vortex proche } \\
\text { - Croisillon de réaction so- } \\
\text { lidaire de la pompe. } \\
\text { - Evite la ulse en rotation } \\
\text { de l'eau. }\end{array}$ \\
\hline & $\begin{array}{l}\text { Panier anti-vortex: } \\
\text { - Solution patentée Peerless } \\
\text { Pumps. } \\
\text { - Panier avec effet stabili- } \\
\text { sateur, anti-vortex. }\end{array}$ \\
\hline & $\begin{array}{l}\text { Piece d'aspiration anti-vor- } \\
\text { tex. } \\
\text { - Evite la alse en rotation } \\
\text { de l'eau. }\end{array}$ \\
\hline SITIo & $\begin{array}{l}\text { LOGIQUES CUVES D'ASPIRATION. } \\
\text { \& I2 }\end{array}$ \\
\hline
\end{tabular}


6. INFLUENCE D'UN CROISILLUIY SITUE A L'ASFIRATIOR D'UNE POMPE

La fonction d'un croisillon peut être double. En effet, ainsi que vu précédemment, il existe au moins deux types d'écoulements tourbillonnaires désordonnēs, contre lesquels le croisillon peut agir.

- Action contre un mouvement tourbillonnaire d'ensemble de l'écoulement, généré par la forme d'aspiration (succession de coudes, chambre d'aspiration mal conçue..)

- Action contre le mouvement de prérotation induit par l'écoulement de recirculation à débit partiel.

Chacun de ces deux cas, dicte à la fois, la forme du croisillon et son emplacement dans l'installation. Par contre, le mode d'action peut être considẻré comme identique puisqu'il s'agit dans tous les cas d'empêcher, le mouvement giratoire ou tourbillonnaire de l'eau et de détruire le moment cinétique de l'écoulement.

\section{Elimination du courant de recirculation}

Le croisillon agit dans ce cas, essentiellement ã dëbit partiel. Au nominal, son effet est nul. La géométrie du croisillon est essentiellement contrôlêe par le dêveloppement du courant de recirculation; il suffit en particulier de quatre ailettes disposées en périphérie à l'intêrieur de la tuyauterie (largeur environ $0,20 \mathrm{D})$ pour obtenir une efficacité importante. Par contre ces ailettes doivent être situées aussi proches que possible de la roue.

\section{Elimination d'un écoulement tourbillonnaire dans la tuyauterie}

Le croisillon doit dans ce cas, intéresser toute la section de la tuyauterie y compris la zone centrale. Son action s'exercera essentiellement à débit nominal et surtout à grand débit. Ce croisillon peut être mis en place à la sortie d'un coude pour détruire le mouvement tourbillonnaire crêe par ce coude, et sá longueur devra être de 3 à $5 D$ environ pour atteindre à une efficacité importante.

\section{Exemples d'utilisation de croisillons}

- Un exemple classique (BERGERON [27] (figure 13) confirme l'influence générale d'un croisillon, sur une pompe de Ns 60 : augmentation de la HMT $(+20 \%)$ et de la stabllité de la courbe.
ZULSES CARACTERISTIOUES

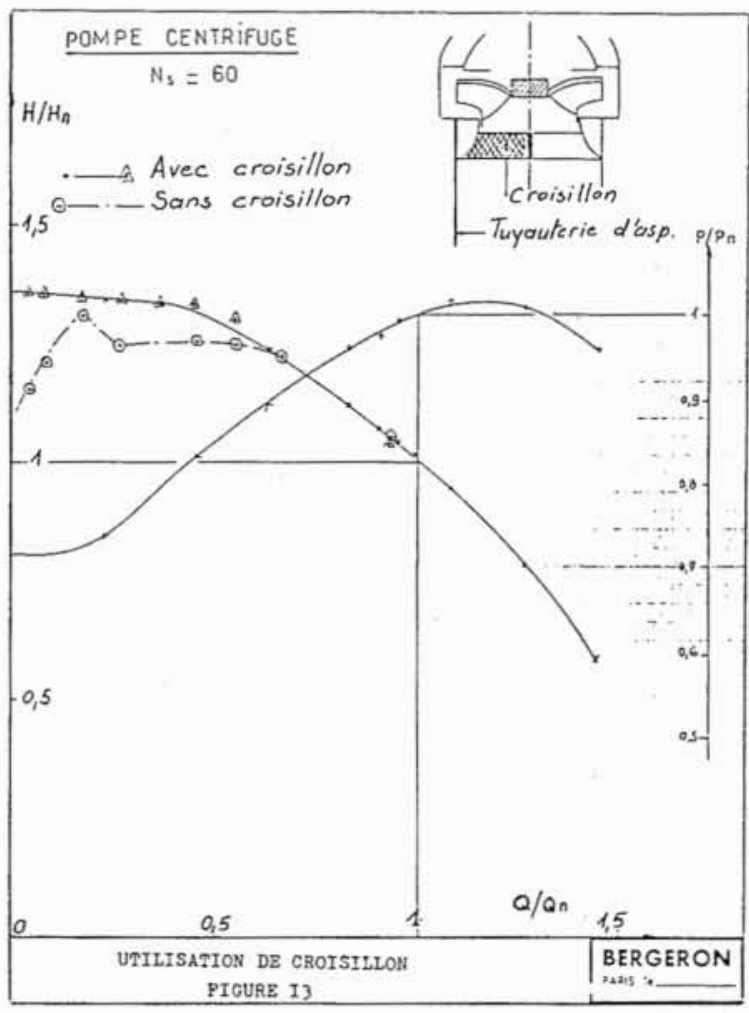

- Un autre essai, sur une pompe de Ns 30 (SULZER [27], figure 14) confirme de façon très intéressante l'importance de la zone annulaire sur le diamètre extérieur de la tuyauterie et l'efficacité des dispositifs qui peuvent y être mis en place : deux mesures comparatives avec croisillon (HMT $+9 \%$ ) et avec quatre petites ailettes soudēes en përiphẻrie immédiatement avant la roue (HMT $+5 \%$ ) permettent de tester l'efficacité relative de ces ailettes sur le tourbillon de recirculation.

- Inversement LIU-DA-KAI [18], dēmontre que la mise en place d'un croisilion libre à I'aspiration d'une pompe, fait chuter la caractêristique $\mathrm{Q}-\mathrm{H}$ ã débit partiel de façon très importante $(\mathrm{H}-35 \%, \mathrm{P}-25 \%)$, par création d'un mouvement de vortex forcé dans le noyau central de l'écoulement dêbitant.(voir fig. 15)

- Une importante étude comparative du CETIM [16], portant sur plusieurs croisillons de forme différente, analyse l'action de ces croisillons sur l'écoulement de recirculation, et confirme l'influence sur la courbe Q-H, le NPSH et la prérotation. Selon ces résultats, il n'y aurait pas de relation évidente entre i'arrêt de la prérotation et le gain de hauteur à dêbit nul.

Il aurait étê intéressant cependant dans le cadre de cette êtude de distinguer l'effet du croisillon sur les deux écoulements - principal débitant et de recirculation, et d'optimiser 
dans les deux cas la forme et l'emplacement de ce croisillon.
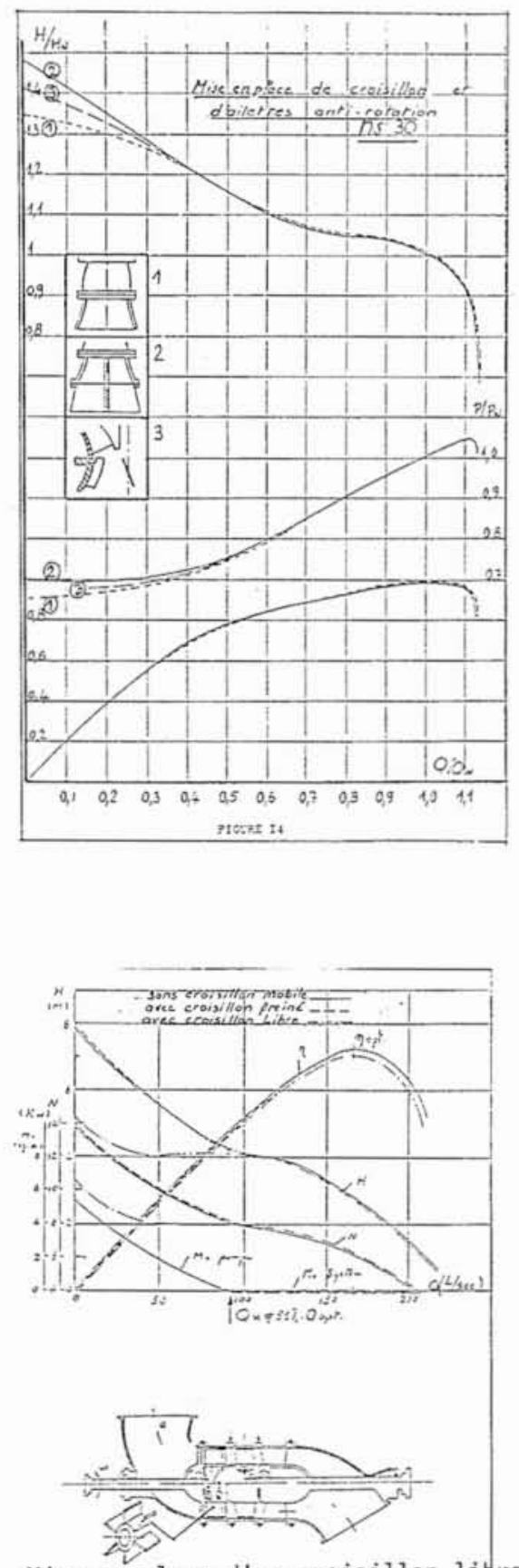

Mise en place d'un croisillon litre à l'aspiration (REF.18)

FIGURE 15

7. EXISTENCE EVENTUELLE DE TROUS D'EQUILIBRAGE DANS LA ROUE.

Il est possible et même probable que la création de trous axiaux d'équilibrage hydrau- lique dans le moyeu de la roue, puisse avoir une influence, à la fois sur la caractéristique Q-H et sur le NPSH requis, ã cause de la perturbation ainsi engendrée sur l'écoulement par ces trous.

On peut penser que cette influence sera d'autant plus importante que le Ns et le dëbit recirculé sont grands.

Quelques exemples expérimentaux permettent de prêciser cette influence.

\section{Expêrimentation J.S}

Des essais paramétriques avec différents dimensionnements de trous d'équilibrage ont été entrepris par un constructeur Jeumont-Schneider sur une pompe monocellulaire, à diffuseur + volute, vitesse spécifique élevẻe (roue hẻlico centrifuge - Ns 110) et aspiration droite.

En dehors des résultats attendus sur la réduction de poussée axiale, ces essais ont montré un accroissement de la hauteur, dans la zone $Q_{0}-Q 25 \%$, avec 1 'augmentation du diamètre de percage des trous. La courbe la plus basse étant la courbe sans trous d'équilibrage.

Il faut noter cependant que si la tendance de cette variation est clairement établie, 1 'augmentation relative de hauteur est cependant faible $(+3,4 \%)$.

Corrêlativement, la variation de puissance est de l'ordre de $8 \%$.

En dehors de cette zone des débits partiels, la variation sur les caractéristiques a été pratiquement nulle, y compris à grand débit.

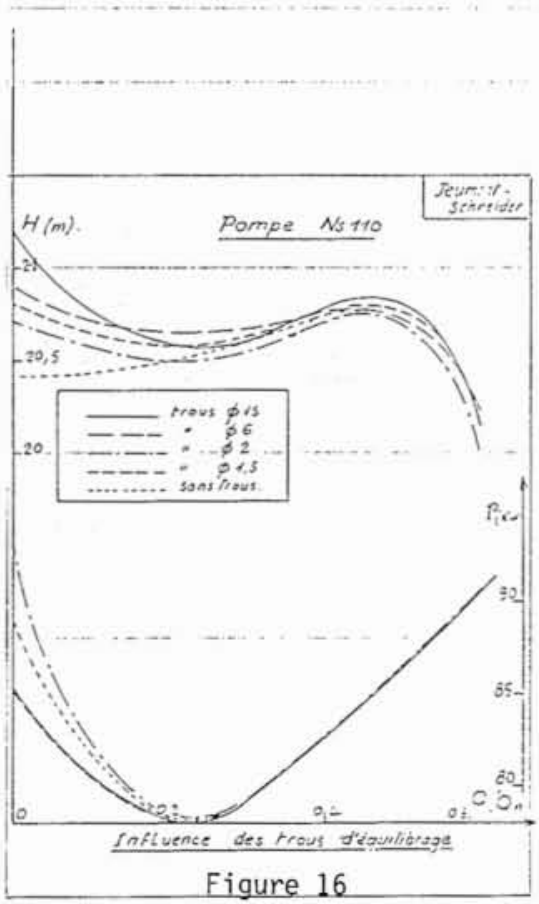




\section{Essais Sulzer}

Deux essais comparatifs faits avec une hydraulique de type centrifuge (Ns 32) montrent une évolution inverse de celle relevêe précédemment, et confirment la tendance gẻnēralement reconnue, à savoir :

- diminution de la hauteur ã vanne fermée dans le cas d'exécution avec trous d'équilibrage - de même que chez J.S, aucune variation sur le rendement (diminution) n'est observée.

\begin{tabular}{|l|c|c|}
\cline { 2 - 3 } \multicolumn{1}{c|}{} & Essai $n^{\circ} 1$ & Essai $n^{2} 2$ \\
\hline \begin{tabular}{l|l|}
\hline Essai de référence \\
Sans trous d'equitibrage
\end{tabular} & - & - \\
\hline Avec trous d'équilibrage & & $-16 \%$ \\
\hline $\begin{array}{l}\text { chute de hauteur \& } Q=0 \\
\text { chute de hauteur d } Q_{P R M}\end{array}$ & $-12 \%$ & $-2,5 \%$ \\
chute de rendenent \& $Q_{P R M}$ & 0 & -1 point \\
chute de puissance a $Q=0$ & $-12 \%$ & - \\
\hline
\end{tabular}

\section{Essais Bergeron}

Un dernier exemple, présenté pour une pompe de Ns 55 avec alimentation par tuyauterie droite montre, dans ce cas, une très faible incidence de ces trous sur la courbe $\mathrm{Q}-\mathrm{H}$ $(-1,4 \%$ ã $Q 25 \%$ et $0 \%$ à vanne fermée). La diminution de puissance par contre, est de 1 'ordre de $6 \%$.

\section{Discussion}

Il est clair ã travers ces exemples, qu'il n'y a pas de règle générale concluant à̀ la diminution de la courbe $Q-H$ dans le cas oũ $i 1$ $y$ aurait des trous d'équilibrage.

I1 semble à travers ces trois essais, que si cette tendance est vêrifiêe pour les faibles Ns, dans le cas de Ns supërieurs la variation de la courbe semble être inversée et conduit à une augmentation de la hauteur de refoulement à débit partiel.

\begin{tabular}{|l|c|c|c|}
\hline \multicolumn{1}{|c|}{ Ns } & 32 & 55 & 110 \\
\hline $\begin{array}{l}\text { Variation de hauteur si } \\
\text { trous equilibrage }\end{array}$ & $-12 \approx$ & $-1,4:$ & $+3,4 \%$ \\
\hline Variation de puissance & $-12 \%$ & -65 & -85 \\
\hline
\end{tabular}

On note, par contre que dans tous les cas,

la puissance diminue de façon importante.

Bien que nous n'ayons aucun résultat d'essai, $i 1$ est probable qu'en conditions de NPSH limite (début de cavitation) 1 'écoulement de retour provenant des trous d'équilibrage puisse perturber le noyau sain de l'écoulement amont.
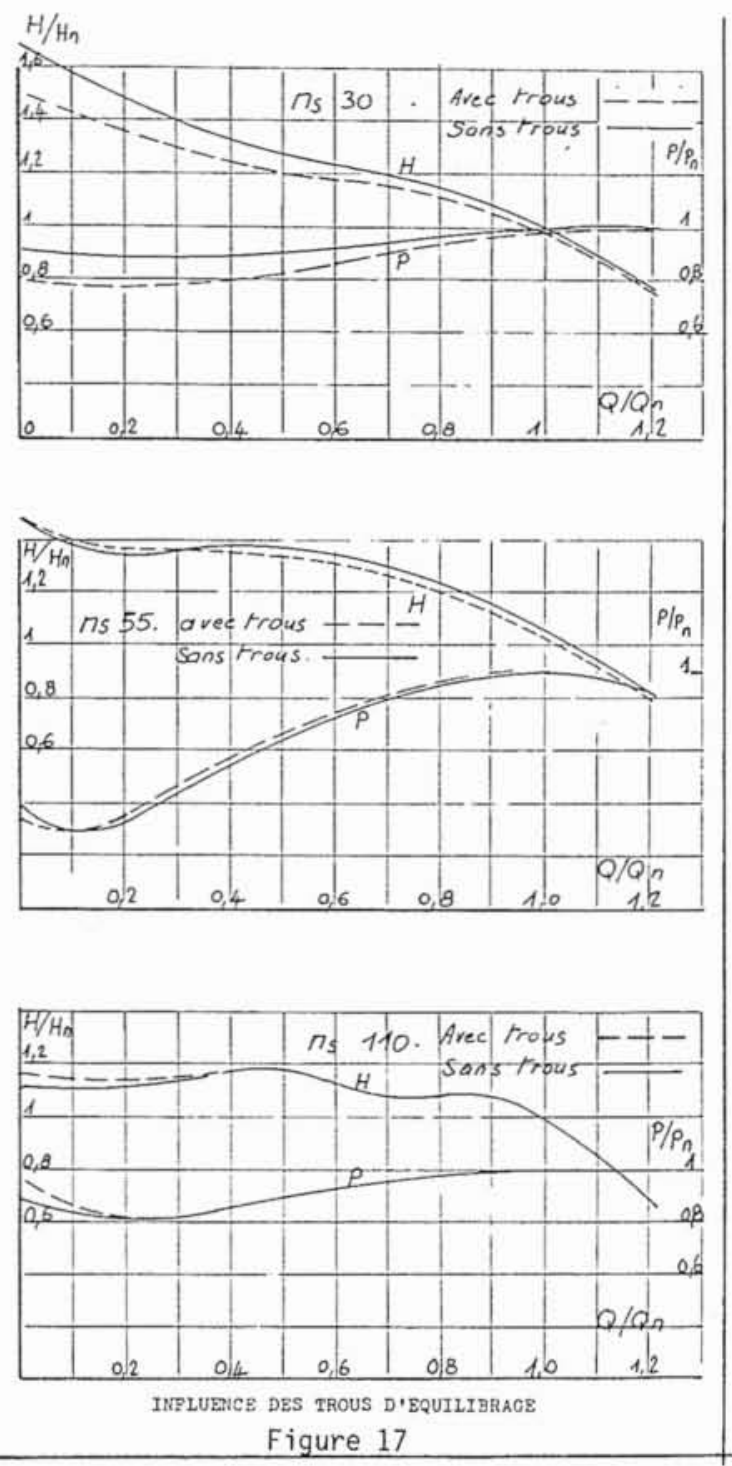

8. POSITION DE L'ARETE D'ENTREE D'UNE ROUE DE POMFE CEITRIFUGE

Influence de 1 'affutage

Des essais effectuếs par Murakami [3] montrent que la hauteur à vanne fermée, est plus êlevée dans le cas d'utilisation d'aubes tri-dimensionnelles. Par ailleurs, la prolongation de l'aube à l'entrée, soit côté plafonc ou côtê ceinture tend êgalement à augmenter la stabilitê de la courbe Q-H dans la zone des débits partiels, mais entraine dans certains cas une légère diminution de rendement Réf \{16]. (voir figure 18).

Divers essais (Réf. 27-12) mettent en évidence également une très grande sensibilité des caractéristiques à débit partiel, dans le cas d'affutage de l'arête d'entrêe. On obtient par cette mêthode une amélioration des caractéristiques de NPSH, mais au dëtriment de la stabilitê de la courbe Q-H et parfois du rendement. (voir figures 19 et 20). 

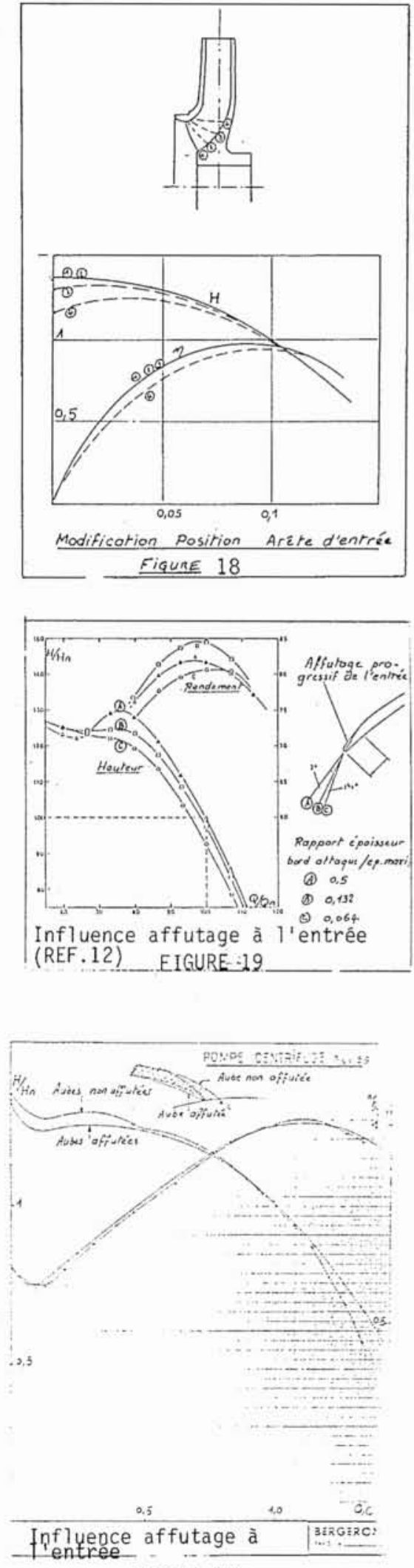

FIGURE 20

\section{WISFOSITIFS D'AREELIORATION EES CARACTERISTIQUES} A DEBIT PARTIEL

L'amélioration des caractéristiques d'une pompe, à débit partiel peut comporter plusieurs aspects :

- diminution de la zone de fonctionnement en recirculation par dēcalage du point Qk vers les petits débits

- augmentation de la hauteur à vanne fermée : ceci peut être rendu nécessaire si l'on veut obtenir des courbes stables, autorisant une marche en parallèle, par exemple.

- au contraire, diminution de la caractêristique de hauteur à vanne fermée (cas des pompes hêlice par exemple) ou de puissance (démarrage de pompes hêlicocentrifuges, et pompes hélices...).

\subsection{Augmentation de 1a hauteur à vanne fermée}

I1 s'agit dans ce cas d'éviter la mise en rotation positive, du noyau central débitant, donc d'isoler le courant inverse de recirculation ou de le dētruire.

Virole d'aspiration : cette virole placée dans Ta tuyauterie d'aspiration limite le courant inverse de recirculation dans un espace annulaire restreint et l'isole de la zone centrale débitante qui n'est plus entrainée en rotation par les forces de viscosité.

Plaques radiales ou redresseuses: le principe d'action de ces plaques est de s'opposer à la prérotation du courant de recirculation qui est dëtruit par réaction, et d'empêcher ainsi le développement du tourbillon central.

Virole + plaques radiales : ce dispositif combine les deux solutions précédentes et son action est identique.

I1 faut noter que l'efficacité de ces systèmes à plaques "anti-vortex" est très importante, et permet donc de corriger des défauts apparus par une mise en oeuvre relativement modeste et donc économique.

Par contre, le couple de réaction s'exerçant sur le stator, il y a risque dans certains cas, de vibrations et de bruits parfois importants.

\section{Etranglement de la roue à l'aspiration}

Des essais faits par Murakami, ont mis en évidence l'existence d'un rapport optimal de blocage pour lequel la réduction de puissance à débit partiel est maximale (jusqu'à $30 \%$ ). Les conditions optimales sont obtenues pour un écoulement correspondant à une entrée sans choc, sur la roue. 


\subsection{Diminution de la hauteur à vanne fermée}

Pour cette action, il est nécessaire par exemple de créer une prérotation positive, dans la zone des débits partiels.

Rouet mobile : ainsi que dẻmontré expêrimentalement par LIU-DA-KAI, la diminution de la caractẻristique peut être obtenue par mise en place d'un rouet mobile avant la roue, tournant librement sur son axe. A débit réduit, et sous 1 'effet de 1'écoulement de recirculation, ce rouet mobile induit un mouvement du fluide, de type vortex forcé dans la zone d'écoulement central.

\section{Trous d'équilibrage}

Bien que la fonction essentielle soit de diminuer la poussée axiale, les trous d'équilibrage permettent au moins dans la gamme des petits Ns de diminuer dans une certaine mesure, la hauteur à vanne fermée.

9.3 Déplacement du point d'apparition de la recirculation

\section{Méthode par jet}

On envoie du fluide sous pression, sous forme d'un jet dirigé vers l'entrée de la roue, en retardant ainsi le décrochage en bout de pales et en diminuant la HMT et la puissance (application aux pompes hêlices).

Une variante consiste au contraire, à prélever du fluide à l'entrée de la roue, ce qui augmente l'effet d'écoulement centrifuge.

\begin{tabular}{|l|l|l|l|}
\hline \multirow{4}{*}{$\begin{array}{l}\text { Dispositif } \\
\text { d'amélioration } \\
\text { à débit partie }\end{array}$} & \begin{tabular}{|l|l|l|}
\hline \\
Figure 21
\end{tabular} \\
\hline
\end{tabular}

\section{CONCLUSION GENERALE}

Il faut mentionner, en dehors de cette rapide étude, I'existence d'autres formes d'aspiration non abordées ici : par exemple flasques d'aspiration pour roues simples ou roues double oeillard, trompettes d'aspiration...

L'êtude de diffërents résultats expérimentaux ci-avant montre qu'à travers des tendances ou des lois générales d'inter-action des écoulements ou d'influence sur les courbes caractéristiques il existe un certain nombre d'exceptions à ces règles qu'il serait intéressant de pouvoir expliciter.

Puisque la caractéristique réelle d'une pompe résulte de l'inter-action entre écoulement incident principal et écoulement de recirculation, il serait nécessaire de vêrifier dans le cas de formes particulières d'aspiration autres que les coudes réguliers, comment se fait cette inter-action et quelle en est l'influence sur la caractéristique.

Enfin, comme Paterson l'a montré dans son étude sur les chambres d'aspiration [11], il est à penser que la proximité et le dimensionnement relatif de l'espace d'aspiration (espace libre ou espace restreint) ont une influence directe sur la diffusion de l'écoulement de recirculation, et ceci quelque soit le type d'aspiration rencontrê (coude, flasque, tuyauterie) ; l'espace d'aspiration interfère avec 1'écoulement de recirculation et transmet au fluide un moment cinētique de réaction plus cu moins important. Un important travail fondamer.tal et expérimental reste à faire pour la compréhension de ces phênomènes.

\section{REFERENCES BIBLIOGRAPHIQUES}

1. Société Hydrotechnique de France - Division Applications Industrielles de la Mécanique des Fluides - Etude des Fonctionnements à débit partiel à faible variation volumique du fluide

Cahier $n^{\circ} 1$ - Texte

Cahier $n^{\circ} 2$ - Notation figure

Cahier $n^{\circ} 3$ - Bibliographie

2. F. FERRINI - Pumps and Pumping Systems for Liquids in Single or Multiphase Flow VOI. III. WORTHINGTON EUROPEAN TECHNICAL AWARD (Hoepli MILAN)

3. MURAKAMI M. and HEYA N. - Swirling flow in suction pipe and centrifugal pumps - Bull JSME, Vol.9 N.34.1966.

- 4. JANIGRO A. and SCHIAVELLO B. - Prerotation in Centrifugal Pumps. Design Criteria. Von Karman Institut.

5. SEN M. - Prerotation in Centrifugal Pumps Von Karman Institue, LS 1978-3, March 1978. 
6. TOYOKURA T., KUBOTA N. - Studies on back-flow mechanism of turbomachines. Bull. JSME, Vol. II.N.43.1968.

7. SCHIAVELLO B. - Débit critique d'apparition de la recirculation à l'entrée des roues de pompes centrifuges. La Houille Blanche $N^{\circ} 2 / 3.1382$

8. MURAKAMI M. and HEYA N. - Improvement of Pump Performance by Impeller Eye Throttling ASME, 69, FE.26.1969.

9. FERRINI - Some Aspects of self-induced prerotation in the suction pipe of centrifugal pumps

10. BONNINGTON - Some Measurements of swirl in pump suction pipes (BHRA rep. $n^{\circ} 526$ )

11. PATERSON ADAMS - Installation effects on wet well pump performance (Stirling 1977)

12. MYLES - Balancing Hydraulic and Manufacturing standards for Pump Progress (Durham 1976)

13. GHEROFF - BORSCHNAKOFF - Experimentelle Untersuchüng der Strömung vor der Eintrittskante des Propellers, unterhalb des besten Maschinen Wirkungsgrad

14. SCHONEBERGER - Beeinflussung des Kavitations beginns bei radialpumpen durch die Zuströmverhaltnisse

15. HUTAREW - Zuleitungen von Kreiselpumpen

16. CETIM - Rapport d'études sur volutes et croisillons (1979)
17. PATERSON NOBLE - The right Approach (Airh-Ams terdam)

18. DAKAI SUNGLING - Effects of inlet construction on the performance and cavitation character of an axial flow pump

19. STOFFEL KRIEGER - Experimental Investigations on the energy balance of radial centrifugal pump Impellers at part load conditions

20. PEKRUN SAXENA - Gestaltung und Untersuchung von Saug-krümmern für vertikale Halb-axial und propeller pumpen

21. BHRA - The Hydraulic design of pump sumps and Intakes

22. Hydraulic Institue

23. FICKELSCHER - Ein Kritischer Vergleich der Verstell propeller un der Drallregelung bei kühl wasserpumpen

24. SAALFELD - Vergleichende Darstellung der Regelung von Pumpen durch Vordrall und durch taufschaufel verstellung

25. SEDILLE

26. BIRD - Vortex Suppressor (Peerless Pumps)

27. Documents fournis par les constructeurs de pompes : BERGERON, GUINARD, JEUMONT SCHNEIDER SULZER

\section{Discussion}

Président : M. le Professeur J. MathIEU

M. Le Président. - Je remercie M. Guesnon de son exposé qui a été fort documenté et intéressant.

Je souhaiterais poser une question qui tient sans doute à mon expérience de l'aérodynamique. En aérodynamique, on fait relativement grande confiance aux coudes aubagés. Jai cru comprendre à un certain moment que vous renonciez au bienfait des aubages parce que vous craigniez des efforts aérodynamiques intenses. En aérolique on utilise cependant très fréquemment de tels coudes.

M. GUESNON explique que les difficultés et les coûts de réalisation industrielle ainsi que leur moindre résistance aux problèmes mécaniques (dilatations transitoires thermiques..) limitent leur utilisation aux petites machines.

M. LEFEBVRE ajoute que, hormis dans les cas de problèmes sur les sites, les pompistes évitent les ailettes en raison de l'augmentation des vibrations à débit partiel et de la chute de rendement à grand débit de leur utilisation.

M. GUITON confirme que les ailettes sont soumises à des efforts beaucoup plus grands à débit partiel en eau qu'en air et qu'elles doivent être plus rigides pour ne pas se détacher au bout d'un certain temps de fonctionnement.

M. Le Président. - Ce qui est quelque peu frappant c'est la confiance qui existe d'un côté et non de l'autre. Je pensais bien que votre réponse mettrait aussi en avant la notion de réalisation et donc de coût.

M. BORCIANI présente un transparent confirmant les résultats présentés sur la figure 7 et montrant l'influence du coude d'aspiration d'une pompe turbine sur les pertes à débit nul. Il constate que lors du fonctionnement en pompe les pertes à débit nul à l'aspiration sont beaucoup plus élevées avec un coude convergent quavec un cône convergent. Il explique cela par l'interférence de l'écoulement avec une masse d'eau stagnante qui tend à se former dans le coude.

Après avoir souligné l'intérêt présenté par l'exposé, $M$. CANAVELIS observe qu'il faut considèrer avec prudence les corrélations établies entre l'écoulement à l'entrée de la pompe et la forme des caractéristiques. Il rappelle que la recirculation à la sortie de la roue détermine l'essentiel de la puissance et de la hauteur faites par la pompe à petit débit. Il suggère de tenir compte de l'interaction entre les recirculations d'entrée et de sortie lors de toute étude ultérieure destinée à approfondir la compréhension des écoulements perturbés.

M. GUESNON approuve la remarque de M. CANAvelis mais fait remarquer que dans les exemples présentés, les géométries étaient inchangées côté refoulement.

M. LAPRAY précise que les phénomènes se produisant à l'entrée prennent d'autant plus d'importance que la vitesse spécifique est élevée. Il confirme l'intérêt de prendre en compte les hautes et les basses pressions dans toute étude future.

En réponse à $M$. CAIGNAERT, M. GUESNON précise que dans les caractéristiques présentées le coude est bien considéré comme faisant partie de la machine. 


\section{ANNEXE}

REGLES DE TRACE POUR CHAMBRES D'ASPIRATION.

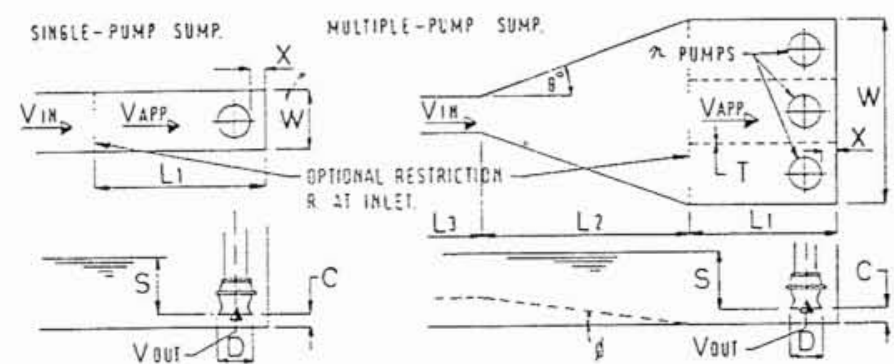

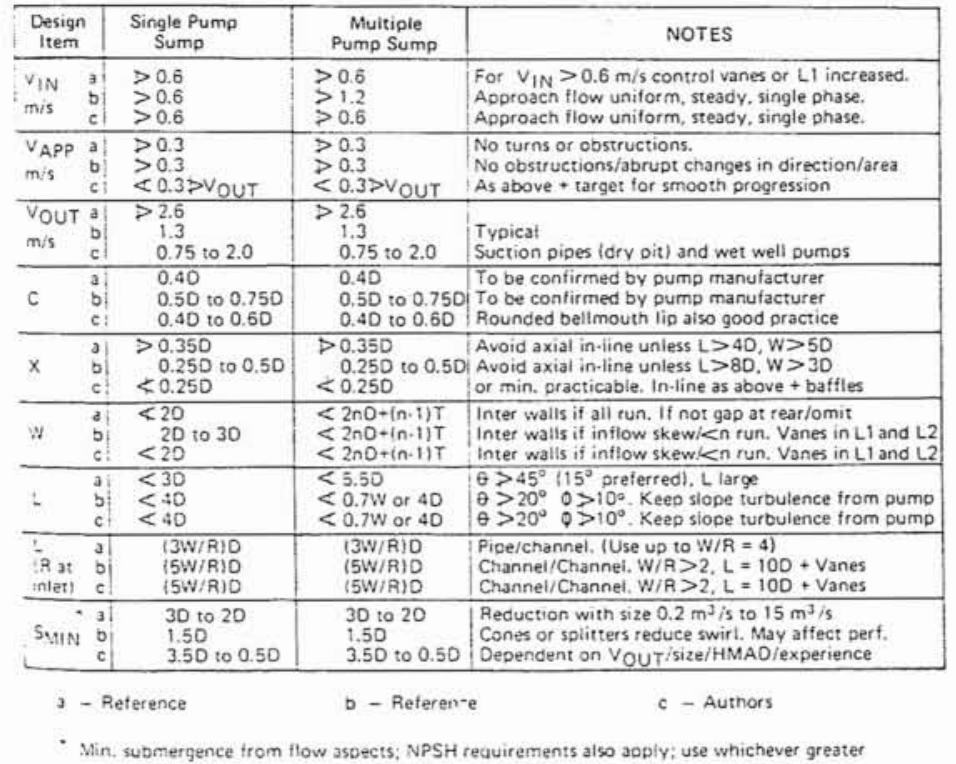

FIG. I SUMP DESIGN RECOMMENDATIONS

COMPARAISON ENTRE HYDRAULIC INSTITUTE, BHRA ET WEIR(PATSRSON).

(REFERENCE $[17]$.PATERSON) 


\section{ANNEXE}

REGLES DE TRACE POUR CHAMBRES D'ASPIRATION.

HOW TO ARRANGE SUCTION PIPE \& THE LIKELYHOOD OF VORT. CALCULATE VORTEX FORMATION ESTABLISHED APPROXIM-

PIPE SUBMERGENCE

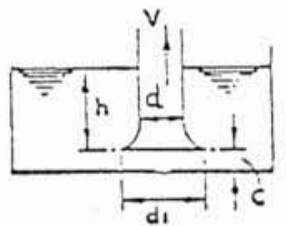

a. IN ORDER TOKEEP SPEED LOW, MAKE C. AS BIG AS POSSIBLE.

b. DIMENSION ' $C^{\prime} \geqq(0.3-0.5)$ $x \triangle$ ZUT SHOULD PREFERABLY NOT EXCSED $0.8 d$.

c. MAKE $d_{1}=1.5 \mathrm{~d}$ (APPROXIMATELY)
VORTEX GRAPH

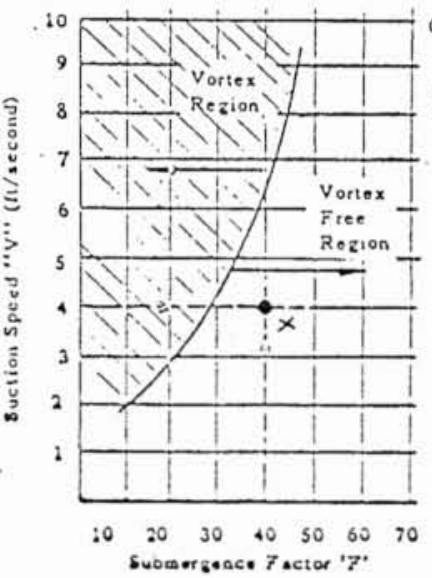
ATEIY FROM THIS GRADH

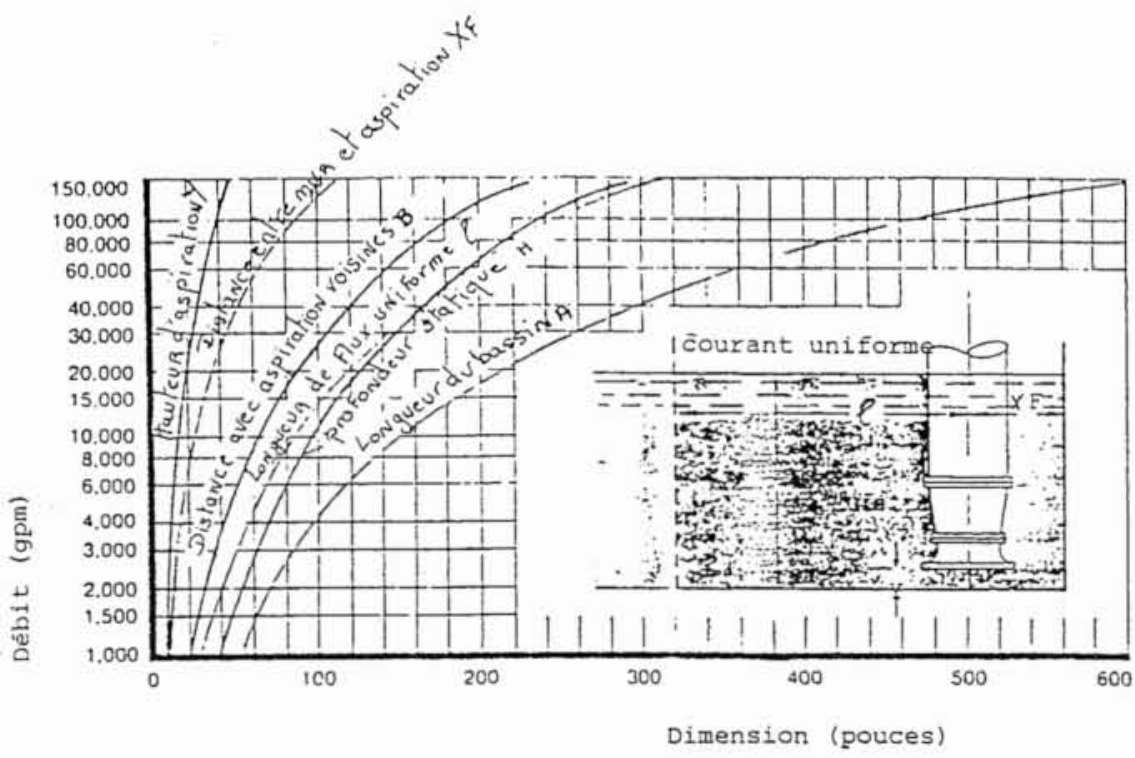
GALCULATE SUBMERG b.BY INTERSECTING THE VALUES FOR F \& SUCTION PIPE SPEEO ' $V$ ' POINT' $X$ 'IS FOUND, INDICATING WHETHER THE OPERATION IS IN THE VORTEX REGION. IN THIS EXAMPLEITIS UNLIKELY THAT A VORTEX WILL FORM $F=\frac{h}{d}\left(\frac{c}{d}+6\right)$

Dimension (pouces) 


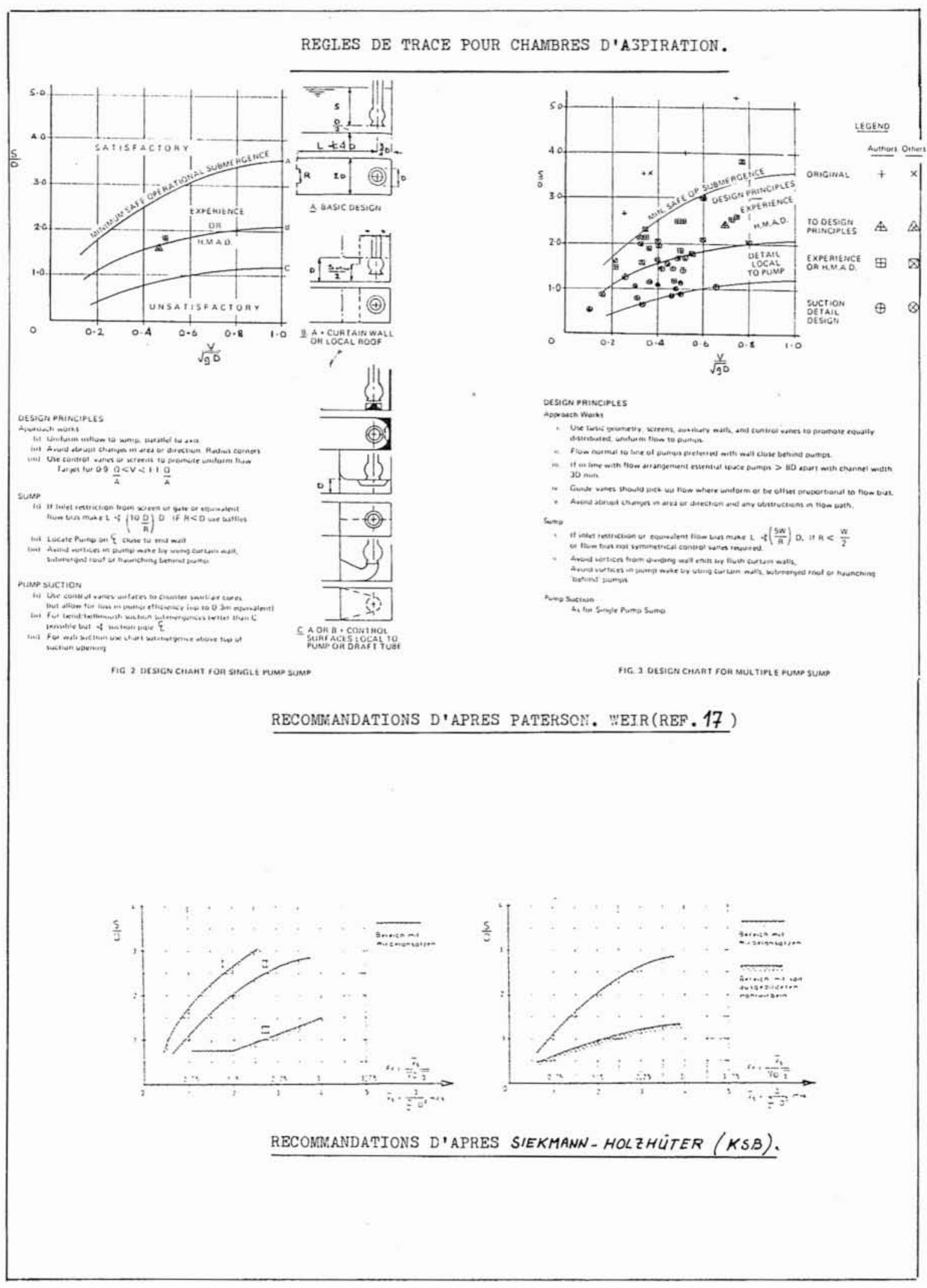




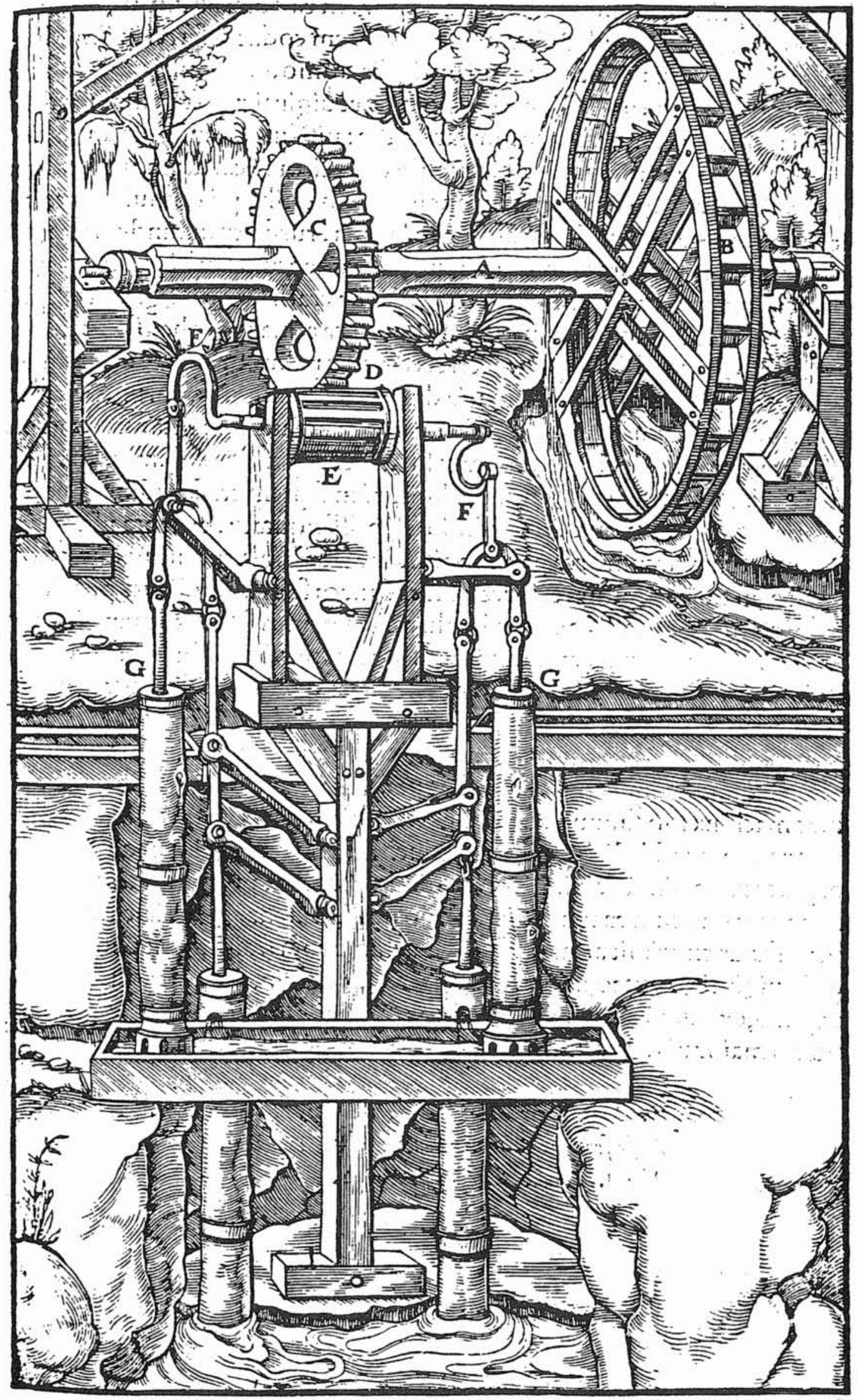

